\title{
Communication Development And Women Rights
}

\author{
M. Shamsuddin \\ Dean Faculty of Arts \\ University of Karachi \\ \& \\ Abida Parveen \\ Sheikh Zayed Islamic Research Centre \\ University of Karachi
}

\begin{abstract}
The prime factor in fostering change and development can be planned by systematic use of communication to help individuals, communities, and societies to accept and introduce changes in a democratic way. Communication is the basis to create awareness, for consensus building, to generate participation in the process of change and development for making informed decision as well as resolving conflicts. It can help individuals to change their attitudes and behaviour patterns, introduce new ideas and practices into their lives to improve their economic and social conditions and to make a positive impact on the society in general. This paper tries to discuss the larger human group of the society as social unit and the effects of development through communication in bringing the social change as well as the women rights recognized by civil and religious laws.
\end{abstract}

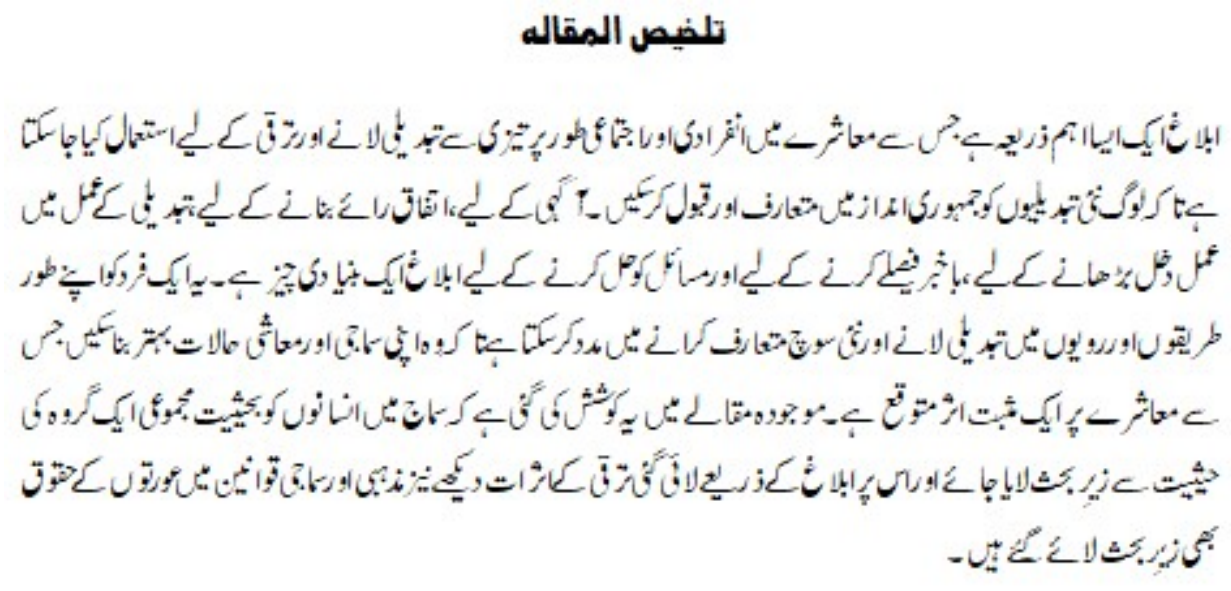

\section{Introduction}

We are living in a period of communication revolution. However, communication alone is not enough, and resources of infrastructure, new technology, investment, etc, are also needed. There is hardly a change and no development occurs without attitudinal and behavioural change of the people. Whether in population programme, protection of 
women rights, poverty, violence, drug abuse, it is a change among the people in their way of living and working conditions that in the end makes the difference. A typical change and development situation usually calls for attitudinal and behavioural change among different broad sectors of society, beginning with policy and decision makers. They create the conditions that favour changes among large number of individuals in a society in general as the ultimate aim. Communication processes for change involve all those groups in an interrelated way, creating interaction and influence between groups and grouping, and primary and secondary groups or society at large.

Society is the largest group in which individuals have relationships. A society refers to a large grouping of people who share common set of habits, ideas, attitudes and consider themselves as a social unit. It is a system of usages and procedures of authority and mutual aid of many groupings and divisions to controls of human behaviour. It is a group of people associated together for some common interest or purpose. It is the sum total of human relationships. A society is a type of social system in any universe of social systems which attains the highest level of self-sufficiency as a system in relation to its environment. Society is a group of people with a common, at least somewhat, distinct culture occupying a particular territorial area, having a feeling of unity and regarding themselves as a distinguishable entity (Summarized from Mohammad Iqbal, 1981).

\section{Some Characteristics of a Society}

It is a larger human group. It satisfies the needs of its members. There are common interest or purpose among its members. There is a consciousness of kindness among the members of a society. It is always changing. It is not subordinate to individuals. These characteristics are interdependent on each other. There are established roots and statutes for its members. It is larger than community, has its own culture. It exists for a longer period of time as compare to or communities. Every society has its own living standards, which are handed down to the next generation. The relationship between an individual and society is mutual and reciprocal (Summarized from Mohammad Iqbal, 1981).

\section{Culture and Society}

Society is a larger organized group of individuals, while culture refers to learned and shared behaviour patterns characteristic of a society. In a way both culture and society are abstracts of human behaviour. Society maintains the social system and enhances its continuation. Mass media trained individuals tell the ways and techniques that cover the entire life of an individual in such a way that he cling to them for the whole of his life. Social system is maintained by mass media. Social structure rests on learning and symbolic communication which is based on normative order. Social structure consists of different parts such as norms, roles, groups, communities, instructions etc. The general

aim of human society is social progress. There are provisions for making the lives of the 
individual richer and fuller in every field. On one hand individuals are provided liberties and privileges, on the other hand they have to perform duties and responsibilities in society.

When two or more persons are in interaction it can be called a group. There should be at least two persons to constitute a group. There must be communication among individuals, physical contacts are not essential for interaction. Persons who have mutual interest make a group by sharing common interests among themselves. There is a social structure (standardized relationships and meanings that arise out of human experiences) which regulates the activities of the group under normal conditions. There is dependence among members. Usually the group is kept small to have a face to face interaction among individuals. Groups are divided into in-groups and out-groups. Individuals living in ingroups develop feelings of oneness and know each other by name, by face, and by occupation. For example, members of a family, playmates or people living in the neighbourhood are emotionally attached with one another. The element of consciousness of kindness dominated in in-groups. In-groups can be primary or secondary. The important point is that its members have a strong sense of identification and loyalty and a feeling of exclusiveness towards non-members.

There are four essentials for primary groups:

1. Close relationship

2. Face to face interaction

3. Direct co-operation

4. Intimacy among members.

Secondary relationships of the individuals are less personal. There is a low degree of intimacy, contacts are casual, and are not based upon permanent feelings.

"A change refers to a state of movements in a given situation either at the time or at more different points in time" (H.M.Rogers, 1971).

A change might be positive or negative, depending on the situation. But these can be changes without development. Development stands for all that is good, positive, and favourable. Development is variably termed as an objective, a programme, movement and a process. Socio-economic change has always intrigued human beings. It is one the most fundamental characteristics of human history. Development, through communication is a particular form of social change, which brings society at par with other societies, enjoying improved living conditions. Many people in developing countries are deprived even of the basic knowledge of their problems. The underlying questions are: what makes societies, nations, communities change? And what makes people change their behaviours, attitudes and ways of life? In view of existing living conditions, in most of the rural areas of the developing societies, development communication has been given considerable attention and is used as an important tool. It is helpful to the rural groups of population in developing societies, like Pakistan where socio-economic improvement are urgently needed. 
Policy makers, teachers, health workers, agricultural assistants and others act as agents of change in a society. They have a key role, as they have continuous contact with the people and are, in fact, the front-line troops in the struggle for development. In most of the developing societies, they rarely have formal training in human relations and communication skills and need to change their attitudes and behaviour to be fully effective. The position of women and children is mainly determined by attitudes and behaviour towards them. Even where women rights are recognized by civil and religious laws in practice, cultural traditions and men's ingrained attitude towards them often deny their proper status. For example, under Muslim Law, men and women have equal rights in marriage, and in all Muslim countries, education for both boys and girls is obligatory. In addition countries have introduced laws to offer better job opportunities for women in the public sector. However, these laws have not generally made much difference in the status of women, and little change is expected, as long as the attitude and behaviour towards women in a society remain unchanged. Although progress has been made in promoting women's rights, much change is still needed.

Globally about $32 \%$ of the work force is made of women, but only $6 \%$ of posts at cabinet level in government are occupied by them. There are 116 countries with no women at the level of political power, and in most of Middle Eastern region, women can neither stand for elections nor have the right to vote. The attitudes of men have allowed discriminatory legislation to remain in force in some countries. Women may not be allowed to own property in their own names. They may have no access to credit. They may not be able to negotiate contracts and sometimes they cannot even exercise their legal rights to inheritance. This is despite the fact that in many developing countries, rural women produce between $50 \%$ and $70 \%$ of the nation's food (Fraser Colin, 1998).

The authoritarian attitudes and disrespect of many men towards women is reflected in domestic violence. According to a report by UNICEF about a quarter of the world's women are violently abused by their husbands or male partners. These figures, according, to a survey are 50\% in Thailand and $80 \%$ in Pakistan Violence accounts for more hospital admission of women than rapes, etc. (Fraser Colin, 1998).

According to a survey fathers often do not send girl children to school. or curtail their education. There are 60 million girls, compared to 40 million boys, who are not enrolled in primary education in developing countries, and $36 \%$ girls enrolled in primary schools continue through to secondary education.

According to a survey by UNICEF, at least 500,000 women a year die during pregnancy or while giving birth, virtually all of them in the developing countries. The vast majority of these deaths could be prevented through relatively simple behavioural change, particularly through women paying more attention to prenatal health care and nutrition (Fraser Colin, 1998). 
These issues have been discussed in various conferences at international level and call for major changes and development through the use of communication to help achieve them. For example in 1992, an action programme emerged from the Earth Summit in Rio de Janeiro which declared that: "Humanity stands at a defining moment in history. We are confronted with a perpetuation of disparities between and within nations, a worsening of poverty hunger, ill health and illiteracy, and the continuing deterioration of the ecosystems on which depends our well-being" (Fraser Colin, 1998).

Nations have realized the role of communication in resolving women issues and call for "raising awareness", "promoting public participation, "empowering communities", "sharing knowledge and experience between communities, "promoting participation in decision making", "education and public awareness campaigns", "promoting the involvement of the local population", "disseminating information"," awareness/training campaigns", through mass media programmes (Summarized from Francois William, 1977).

Human relations exist and develop through communication. Communication means conveying people not just with words and symbols, pictures and print nods and backs, postures and plumages, but to convey take a move that catches their eye and every sound that resonates upon another ear. Interaction, interchange, dialogue, sharing, communion and commonness are ideas that crop up in an attempt to define communication. The word is derived from Latin "communes", meaning "common". The notions of commonality and community are stressed in talking about communication. Thus, "communication is a process which increases commonality but also require element for it to occur at all" (Mc. Quail Denis, 1975).Communication by itself does not increase commonality nor does it need commonality for occurrence. A common language, for instance does not necessarily bring people together. There are other factors too that play in the process of brining about a sense of commonality and more significantly, a sense of community. Thus, communication presupposes a shared symbolic environment, a social relationship among those who participate. What it leads to is social interaction among and in combination with a set of other factors, contributes a sense of community? (Mc. Quail Denis, 1975).

Communication for social change is as old as organized society. Although communication for development came into being in 1960, and has clearly shown its usefulness and impact in change and development actions, its role is still not understood and appreciated to the point that it is routinely included in development planning.

"Without communication the mind does not develop a true human nature, but remains in an "abnormal and nondescript state, neither human nor properly brutal" (Cooly Charles H, 1966). 
Different experience happens more gradually to all human beings and it is through communication that human mind is developed. The forces and conversation with associates; books, letters, travel, art and the like by awakening thought and feeling and guiding human beings in certain channels, supply the stimulus and framework for all its growth. In this way the life of a social group is affected by communication "No innovation, however, brilliantly designed and set down plan of operations, becomes development until it has been communicated" (Fracer, 1998). No input or construction of material reassures for development can be successful unless and until the innovations of new techniques and changes in surrounding attitudes which people will need to use as resources to be communicated to them.

Communication for development has three different and separate but related components: social communication, educational communication and institutional communication. Communication promotes dialogue, reflection, participatory solution analysis, consensus building, decision making and planning action for change in the communities. Communication is the process of mobilizing people and communities and helping masses to gain the insight and confidence needed to tackle various problems. Communication helps masses to obtain knowledge and skills required to bring a change and development decisions into action. Communication creates the flow of information inside and between all people involved in development actions including governments, women organizations, NGOs and communities. Through communication an understanding of the social issues including women problems, can be created. Colin Fraser sum up by saying:

"Communication for development is the use of communication processes, techniques and media to help people towards a full awareness of their situation and their options for change, to resolve conflicts, to work towards consensus, help people plan actions for change and sustainable development, to help people acquire the knowledge and skills they need to improve their condition and that of society, and to improve the effectiveness of institutions"(Fracer, 1998).

More than 50 per cent population in the world consists of women. It is therefore necessary to realize the importance of women in society and their welfare and rights and progress be attained through means of communication. This is an issue, which throughout history, has bristled with emotional complexes, traditional taboos and other complications. Historically, the status of women has undergone many changes. She has been men's help mate without whom their lives would never have been complete. Anwar Abbas says "in some cultures the status of woman was better recognized at one time or at least in one direction, and then there was a regression, sometimes, within the same state or religion the position of women has differed enormously. Economic factors, technical advances, social theories and religion have influence it. (Abbas Anwar, 2007). 
Sometimes there has been a great gap, greater than in the case of men, between the theoretical rights enshrined in personal law or constitution and those accorded in practice. The right to share in property has been denied to women by hidebound men of feudal and semi-feudal societies.

The status of women before the advent of Islam was not enviable, either in Arabia or outside. In the great Greek civilization woman was created as a slave. In Roman civilization, too she had a low status under the law. Even in Jewish and Christian religions woman was supposed to be a source of pollution. The history of monks is full of painful incidents of how they looked down upon women. In Arabia before the advent of Islam, women were mere objects of pleasure or slaves to carry out the commands of men.

"With the advent of Islam, the situation regarding the status of woman in society changed. There are many verses in the Quran as well as the sayings of Holy Prophet which helped greatly to raise women's position and gave her many, hitherto denied rights. The first thing that Islam did was to declare that there is equality between the sexes. To Islam it was not merely a matter of rights but also of decent behaviour. Man must learn to treat women with respect and consideration as well as with a sense of Justice in both economic and social relations" (Abbas Anwar, 2007).

There are many verses in the Quran coupled with the saying of Holy Prophet (PBUH) which helped greatly to raise status of women in society and give her many denied rights. Islam gives genuine equality between the sexes and no community could build up the fabric of good life if their mutual relations were not rightly ordered. Man must learn to treat women with respect and consideration as well as a sense of justice in economic and social relations.

"O ye who believe! Ye are forbidden to inherit women against their will. Nor should ye treat them with harshness, that ye may take away part of the dower ye have given them except where they have been guilty of open lewdness; on the contrary live with them on a footing of kindness and equity. If ye take a dislike to them it may be that ye dislike a thing, and Allah brings about through it a great deal of good" (Quran, 4:19).

The Prophet always showed consideration and gentleness to women, whether belonging to his family or were from outside. For instance, he always stood up to show respect for his beloved daughter, Fatima. In other ways, in an era when infanticide was in vogue and women were considered as 'property'. In his last sermon, made a few months before his death, the Prophet (PBUH) worked upon it, as if it was a covenant with God: "Fear the displeasure of God in the matter of women". On another occasion he remarked that the best of men (before God) is he who deals with his family in the gentlest possible way, and "he is the best of believers who is courtesies and treats his dependents gently" (Abbas Anwar, 2007). 
The Quran does not restrict itself to recommending gentle behaviour towards women but also gives specific instructions about what this connotes in the matter of inheritance, marriage, divorce, etc. It lays down detailed guidance about how property was to be distributed among the relations and dependents of a deceased individual, giving due share to both men and women, the latter being allotted half of the share as allotted to man, presumably on the assumption that they were entitled to inherit well as their husbands (Abbas Anwar, 2007).

It is stated in the Quran: "From what is left by parents and those nearest related there is a share for men and a share for women, whether the property be small or large- a determinate share" (Quran, 4:7).

Elsewhere, the Quran states: "And in no wise covet those things in which Allah hath bestowed His gifts more freely on some of you than on others: to men is allotted what they earn, and to women what they earn: but ask Allah of His bounty. For Allah hath full knowledge of all things" (Quran, 4:32).

The above verse clearly shows that women have the right to earn their living and are entitled to keep what they have earned and no one can forcibly take it away from them. Islam laid down in must social, economic and other matters the broad principles that should govern the relations among individuals, groups and communities.

The mass media have a responsibility to advocate these principles and to bring a change in the attitude of men by dialogue and planning at action for change and development. Social communication is the process of mobilizing people and communities, and also helping people to gain the insight and confidence required to tackle their problems. Both formal and informal education is indispensable to changing men's attitudes so that they have the capacity to assess and address their sustainable development concerns.

It is necessary to achieve ethical awareness. Education should employ both formal and non-formal methods and effective means of communication. Greater knowledge and commitment at all levels, from the individual to the international level are vital to the achievement of goals and objectives of the present situation of women rights. In all countries and groups, therefore, information, education and communication activities, concerning women rights must be strong. "Information, education and communication efforts should raise awareness through public education campaigns on priority issues such as safe mother hood, reproductive health and right, maternal and child health, family planning and discrimination against the girl child" (Park Robert). More education is needed in all societies on the implication of women rights in order to influence behavioural change. The media should be a major instrument for expanding knowledge and motivation. 
Mass media are the tools of communication. The history of civilization has marked a progressive increase in the radius of communication. Communication creates or makes possible, at least, that consensus and understanding among the individual components of social groups, which eventually gives it the character not merely of society but of a cultural unit. Communication maintains the concern necessary to enable groups to function. Thus, the function of communication seems to be to maintain the unity and integrity of social groups into two dimensions space and time. Johan Dewey said "society not only continues to exist by transmission by communication, but may fairly be said to exist in transmission to communication" (Park Robert).

Dewey's statement is a conception of society that is not generally accepted since it seems to identify the social with the moral order. In this way the term social limits it to those relations of individuals that are personal, customary, and moral.

"When individuals use one another to get results, without reference to their emotional or intellectual disposition and consent," says Dewey, "they are involved in relations that are not social". To make the matter more clear, he adds, "So far as the relations of parent and child, teacher and pupil, remain upon this level, they form no true social group, no matter how closely their respective activities touch one another" (Park Robert).

However, it is clear that communication is the typical social process and the only form of interaction that goes on among the individual unit of a social group. "We are compelled to recognize," Dewey admits, "that even within the most social groups there are many relations which are not yet social" at any rate, in the sense in which he uses the term. Competition, for example, performs a social function of a somewhat different sort, but one that is, at least, comparable to that of communication. The economic order in a society seems to be very largely a by-product of competition. In any case, competition is, as Cooley observes, "the very heart of the economic process." What we ordinarily designate as economic competition, however, this competition is not in the Malthusian sense of that term which is identical with the struggle for existence. Economic competition is always a competition that is controlled and regulated, to some extent, by convention, understanding, and law (Fracer, 1998).

The role of communication has been so important for any population that in 1994, the Conference on Population and Development in Cairo recognized it. Its action plan states:

"Information, education and communication efforts should raise awareness through public education campaigns on priority issues such as safe motherhood, reproductive health and rights, maternal and child health, family planning, discrimination against and valorisation of the girl child More education is needed in all societies on the implications of 
population-environment relationships, in order to influence behavioural change and consumer lifestyles and to promote sustainable management of natural resources. The media should be a major instrument for expanding knowledge and motivation" (Fracer, 1998).

Communication takes place through the medium of gesture, articulate speech or conventional symbols of any sort and involves interpretation of attitude or intent of the person whose word or gesture supplied the stimulus. Communication is a process or form of interaction that is interpersonal. The process is complete when it results in some sort of understanding that communication is expression, interpretation and response. Men and women have learned more in the sense of understanding another and in the ability to communicate. The World Summit a Social Development in 1995 devoted much attention to rectifying social integration and the ills of its causes, and recognized the role of communication for doing so.

The UN defines a socially integrated society as one that is capable of providing space for the aspirations of individuals of different and divergent groups, within a flexible structure of shared basic values and common interests. Social integration is synonymous with greater justice, equity, material well-being, democratic freedom, and more equal opportunities and rights for all (Fracer, 1998).

The Summit's Declaration and Action Plan committed governments to promote respect for democracy, law, order, pluralism, diversity, non-violence and solidarity through educational systems and mass media. Governments also agreed to promote access to indispensable means of improving communication and increasing participation in civil, political, economic, social, and cultural life. Furthermore, the Social Summit recognized the importance of giving everybody access to a wide range of information and opinions concerning issues of public interest. In this context, governments agreed to use mass media to improve understanding and public awareness of all aspects of social integration, and at the same time to promote the fight against poverty (Fracer, 1998).

The Platform for Action of the Fourth World Conference on Women, held in 1995, identifies the mass media as having 'a great potential to promote the advancement of women and the equality of women and men'. It states that 'television especially has the greatest impact on young people and, as such, has the ability to shape values, attitudes and perceptions of women in both positive and negative ways'. A whole section of the platform devoted to women and media urges more gender sensitivity and elimination of gender stereotyping in programming, as well as to incorporate more women at decisionmaking levels in media operations.

In other sections, the platform calls for education and information programmes, particularly in conjunction with mass media that makes the public, particularly parents, aware of the importance of non-discriminatory education for children and equal sharing 
of family responsibilities by girls and boys'. It also signals the need to modify social and cultural patterns of conduct of men and women and to eliminate prejudices, customary practices and all other practices based on the idea of inferiority or superiority of either of the sexes and on stereotyped roles for men and women (Fracer, 1998).

Communication and public debate provide the avenue by which, at least, in democratic societies, individuals and societies become aware of the issues at stake and adopt new behaviour patterns, in their own interests and in those of the society. Communication can also help them acquire technical skills that are needed to implement change and development. Furthermore, even if human ingenuity comes to the rescue and provides solutions for humanity, as many people believe it will, they will not create stability, if people do not have access to those solutions which are related to women issues. Equity is the basis for stability.

No change in attitudes in respect of women rights becomes development until it has been communicated James P.Grant, the Executive Director of UNICEF wrote:

"Social development is linked to the concerted public action. No matter how valid and worthy the cause, little progress is made in achieving it until a ground swell of public support is built up and diverse sectors of society become actively involved in the process of change" (Fracer, 1998).

He further said:

"An unprecedented gap now exists between what could be done and what is being done to overcome the worst aspects of poverty that claim the lives of 35,000 children a day. The gaps between what is and what could be... are not likely to be closed by any automatic or inevitable process of social development; they are closed most often by the commitment and action of large and growing numbers of people who begin to exert pressure for change... Communication [is] an essential part of this process. Serious advances [can] only be made when large numbers of people begin to know more, care more, and do more. Fortunately, we live in a communication epoch in which mass media are constantly expanding their outreach and influence" (Fracer, 1998).

It is recognized that social progress can take place only as a result of attitudinal and behavioural change across broad sectors of a society. Integrated communication based on mass media, group media, traditional and folk media, and interpersonal channel is the usual tool of social mobilization. The mass media offered quickest and easiest way to reach information that could create awareness on a necessary scale. The media system promote the objective of generating, informed and conscious participation to all of the development process and provides orientation and training to staff and improve institutional cooperation and management. 
Men and women have learned a great deal about one another from experience, but they have learned more in the sense of understanding one another and in the ability to communicate. Communication gives us intimate personal and inside knowledge of each other which makes social life more amiable and collective action possible. Communication is increasingly seen as having an even more, central, if not decisive, role in creating the kind of international climate which can promote the realization of peace, recognition of human rights and solution of other global problems. These matters need a continuous consideration on how communication develops in content and quality?

A vast majority of people in developing societies live in rural areas and depend on production is highest in Asia, Africa with women contributing $60 \%$ to $80 \%$ of labour. It is estimated that up to one-third households around the world are headed by women, a result of migration patterns that pulled men towards cities (Fracer, 1998).

Although women's economic activities and household maintenance functions fall squarely within development programmes, are oriented towards men. Prevailing development patterns favour men as capital intensive development strategies push women out of income earning labour, and as manufactured goods compete with women's income-earning crafts.

Women's access to agricultural extension and credit is always less than men's, as case studies demonstrate. Women household heads face particularly acute access problems. New technology by passes or belatedly addresses women's work. Planners and practitioners assume that men are the sole providers and that modernization hinges on men assuming the primary productive role. Where programs exist for women, they tend to be narrowly oriented towards their roles as mother sand wives. For example, family planning and traditional home economics, except in the most industrialized countries, where little gaps exist in literacy and educational achievement between the sexes.

\section{Conclusion}

A consequence of these patterns is that men acquire disproportionate access to and control over fundamental information, resources, and opportunities. Thus, development not only ignores women but also tends to increase disparities between the sexes. Male preference is expected to take its toll on women's productivity, program effectiveness, and ultimately, development. The women in Development strategy rests on creating more rational and even-handed planning which takes into account the division of labour, fair returns for labour, and the equitable infusion of new opportunities and resources to all members of a given community without discrimination. 


\section{References:}

Abbas, Anwar. (2007) Status of Women in Islam, Editorial in Daily Dawn, (Karachi), 16 March.

Cooly, Charles H. (1966) "The Significance of Communication”, in Berlson, Bernad and Janowitz, Morris, Reader in Public Opinion and Communication, $2^{\text {nd }}$ ed, The Free Press, London.p.147.

Fraser, Colin and Estrada, S. R. (1998) Communicating for Development: Human Change for Survival, I.B, Tauris Publishers, London. p.27-28,25-29, 3,45,63,35.

Iqbal, C. M. (1981) Imraniyat (Sociology), Abbas Ali Printers, Pasia Akhbar, Lahore Chapter 2, p. 49-65

McQuail, Denis. (1969) Towards Sociology of Mass Communication, London: Collier Macmillan. London, p.10, 11-15.

Park, Robert E. (1938) "Reflection on Communication and Culture", in The American Journal of Sociology, Volume XLIV, September, p.167-168,36.37,67-68,189.

Rogers, E. M. Floyd, Shoemaker. F. (1971) Communication of Innovations; A Cross Cultural Approach, The Free Press, New York. p.18.

Shirkat Gah,( 1998) Information Kit: Women In The Quran, Shirkat Gah, Lahore 4:19, $4: 7,4: 32$.

William, Francois E. (1977), Introduction to Mass Communication and Mass Media, USA: Grid Inc, USA, p. 3-21.

Professor Dr. M. Shamsuddin is Dean, Faculty of Arts, University of Karachi, Pakistan. His field of expertise is Communication and Development.

Dr. Abida Parveen is Assistant Professor in Sheikh Zayed Islamic Research Centre. Her area of expertise is communication and Islam. 